ARTIGO

DEREVISÃO

\title{
Reabilitação e condicionamento físico após transplante cardíaco
}

\author{
Guilherme Veiga Guimarães ${ }^{1}$, Fernando Bacal $^{2}$ e Edimar A. Bocchi² \\ Unidade de Insuficiência Cardíaca, Instituto do Coração, HC/FMUSP - São Paulo, SP
}

\section{RESUMO}

Nas últimas décadas a prática regular de atividade física tem sido estimulada entre pessoas saudáveis e pacientes cardiopatas. Os programas de reabilitação cardíaca têm objetivos profiláticos e terapêuticos. Entretanto, existem poucos relatos de programas de reabilitação e condicionamento físico pós-transplante cardíaco no Brasil. O presente trabalho relata a experiência dos autores com pacientes pós-transplante cardíaco submetidos a programa de reabilitação física, na fase hospitalar e pós-alta hospitalar em programas de condicionamento físico supervisionados e não supervisionados. Finalmente, é apresentado o guia de reabilitação e condicionamento físico pós-transplante cardíaco, com indicações e contraindicações para o procedimento.

Palavras-chave: Exercício físico. Transplante cardíaco. Reabilitação.

\section{ABSTRACT}

\section{Rehabilitation and physical training after heart transplan- tation}

In the last decades, the regular practice of physical activity has been stimulated among healthy people and cardiac patients. Cardiac rehabilitation programs have prophylactic and therapeutic objectives. However, there are few reports of rehabilitation programs and physical training after heart transplantation in Brazil. The present paper reports the authors' experience with patients after heart transplantation, undergoing a physical rehabilitation program, in-hospital and ambulatorial phases, in physical training programs, both supervised and non-supervised. Finally, a guide of rehabilitation

1. Fisiologista do exercício.

2. Cardiologista.

Endereço para correspondência:

Guilherme Veiga Guimarães

Rua Dr. Baeta Neves, 98

05444-050 - São Paulo, SP

E-mail: gvguma@usp.br and physical training post heart transplantation is presented, with indications and contraindications to the procedure.

Key words: Physical training. Heart transplantation. Rehabilitation.

Um número crescente de evidências demonstra, com algumas controvérsias, que a inatividade física e os maus hábitos de vida, como a alimentação inadequada, tabagismo, estresse emocional e consumo excessivo de álcool, provocam uma séria ameaça a nosso organismo, podendo causar alterações na capacidade funcional. Assim, problemas comuns e sérios, como a doença arterial coronariana, hipertensão arterial, obesidade, ansiedade, depressão, sedentarismo e problemas de coluna, têm sido relacionados, direta ou indiretamente, com o estilo de vida ${ }^{1,2}$.

A atividade física regular tem tido um papel importante na melhora da qualidade de vida, tanto para indivíduos saudáveis como em pacientes cardiopatas, quer seja na fase primária como na secundária da doença cardíaca.

Os pacientes cardiopatas submetidos ao transplante cardíaco (opção de tratamento para o estágio final da insuficiência cardíaca congestiva refratária à terapêutica medicamentosa) apresentam melhora da qualidade de vida pós-transplante. Porém, frequientemente apresentam similares problemas clínicos no pós-operatório, como o descondicionamento físico, atrofia e fraqueza dos músculos e menor capacidade aeróbia máxima, decorrentes em parte da inatividade pré-operatória e de fatores como diferença de superfície corporal doador/receptor e denervação do coração $0^{3,4}$. A terapia imunossupressora, que ajuda o receptor a tolerar o coração do doador, limita ainda mais a capacidade física, assim como os episódios de rejeição ou sintomas que sugiram redução do desempenho cardiocirculatório ${ }^{3}$.

A atividade física regular tem um papel importante na terapêutica não medicamentosa dos transplantados, devendo ser iniciada o mais precocemente possível na fase hospitalar, dando prosseguimento pós-alta hospitalar, para que possam retornar a um estilo de vida semelhante ao que tinham antes da doença, permitindo convívio social satisfatório, com vida ativa e produtiva $^{5}$. 
Na fase hospitalar, dá-se início ao programa de condicionamento físico, assim que ocorra o restabelecimento hemodinâmico e o desmame das drogas endovenosas dos pacientes, exceto aqueles que transitoriamente apresentem uma contraindicaçã $0^{4,5}$. Essa fase pode ser considerada como o processo de restauração física, psicológica e social dos transplantados. O programa de reabilitação física utilizado nesta fase é o proposto pela Universidade de Stanford, que consiste em exercícios aeróbios em cicloergômetro, começando com cinco minutos de duração, com progressão diária até 25 minutos, velocidade de 40 a 60rpm em carga livre; a partir daí, será introduzida carga com aumento gradual e progressivo e/ou caminhada em esteira/corredor, iniciando com dez minutos de duração, com aumento diário até 30 minutos, com velocidade de 1,5 a $3 \mathrm{mph}$ ou 40 a 80 passos/min., ambos com monitoração da frequiência cardíaca, do cansaço subjetivo (escala de Borg) e da pressão arterial em repouso, na metade, no final da atividade e na recuperação. Em nossa experiência nessa fase, além do programa aeróbio proposto, também iniciamos um trabalho leve de mobilidade articular, de flexibilidade e de resistência dos grandes grupos musculares.

A denervação do coração transplantado resulta em perda do controle direto do sistema nervoso autônomo com alterações hemodinâmicas, respiratórias e metabólicas em repouso e durante o exercício (tabela 1). Portanto, é importante ressaltar que, em função da denervação, no início do exercício e no exercício submáximo, a resposta da elevação do débito cardíaco é mediada pelo aumento na pré-carga, via mecanismo de Frank-Starling, e o aumento da frequiência cardíaca e da pressão arterial durante o exercício passa a depender do nível de catecolaminas circulantes, e isso está relacionado com a massa muscular envolvida, bem como com a intensidade e duração da atividade física ${ }^{6,7}$.

$\mathrm{Na}$ fase pós-alta hospitalar, quando a capacidade física geralmente é desconhecida, recomenda-se a utilização de exer-

\section{TABELA 1}

Respostas hemodinâmicas, respiratónias e metabólicas pós-transplante cardíaco

- Freqüência cardíaca de repouso elevada

- Retardo na elevação da freqüência cardíaca no início do exercício

- Retardo na recuperação da freqüência cardíaca pós-exercício

- Fração de ejeção em repouso diminuída

- Fração de ejeção durante o exercício diminuída

- Débito cardíaco em exercício diminuído

- Diferença arteriovenosa de repouso aumentada

- Consumo máximo de oxigênio diminuído

- Elevação do lactato sanguíneo no repouso e no pico do exercício

- Equivalente ventilatório de $\mathrm{O}_{2}$ e $\mathrm{CO}_{2}$ elevados no exercício cícios de baixa intensidade, três vezes por semana, com sessões de 60 minutos, mantendo-se o padrão da fase hospitalar, com o intuito de melhor adaptação hemodinâmica e muscular. Após um mês da alta hospitalar e maior adaptação funcional do transplantado, recomenda-se a realização de um teste de esforço, de preferência com ergoespirometria, para avaliar a capacidade cardiopulmonar e para prescrição individualizada de intensidade em um programa de condicionamento físico adaptado às condições físicas do paciente.

Entretanto, a intensidade adequada para o treinamento físico de transplantados ainda não está bem estabelecida. Certos métodos têm sido sugeridos por alguns autores para a prescrição de atividade física, como percentual da freqüência cardíaca máxima alcançada, percentual da freqüência cardíaca mais escala de Borg, percentual do consumo máximo de oxigênio e limiar ventilatório ${ }^{5-8}$. Independente do método de prescrição utilizado no programa de condicionamento físico regular póstransplante cardíaco, os pacientes têm obtido resultados benéficos, que são descritos na tabela 2.

$\mathrm{Na}$ experiência do Instituto do Coração (InCor), o programa supervisionado de condicionamento físico pós-transplante cardíaco em adultos e crianças, pós-período de adaptação, englobava exercícios de alongamento, mobilidade articular, de resistência, exercícios aeróbios e de relaxamento. A duração do programa foi de 64 semanas, com sessões de 60 minutos três vezes por semana. A intensidade da atividade aeróbia foi prescrita entre o limiar anaeróbio e o ponto de compensação respiratório obtidos no teste ergoespirométrico. $\mathrm{O}$ aumento de intensidade durante o programa foi feito de forma progressiva, levando-se em conta a freqüência cardíaca, pressão arterial, escala de Borg e os episódios de rejeição. A sessão foi dividida em cinco minutos de aquecimento, com exercícios gerais e de alongamento, 30 minutos de exercício aeróbio, bicicleta estacionária ou caminhada/corrida em sessões alternadas, cinco minutos de recuperação ativa, 15 minutos de exer-

\section{TABELA 2}

Benefícios do condicionamento físico pós-transplante cardíaco

- Redução da freqüência cardíaca de repouso

- Redução da freqüência cardíaca no exercício submáximo

- Aumento da freqüência cardíaca máxima

- Aumento do consumo máximo de oxigênio

- Redução do equivalente respiratório de $\mathrm{O}_{2}$ e $\mathrm{CO}_{2}$ no exercício submáximo

- Retardo na elevação do lactato durante o exercício

- Diminuição dos níveis sistólicos e diastólicos da pressão arterial no repouso e em exercício submáximo

- Redução da gordura corporal

- Melhora do perfil lipídico

- Melhora do perfil psicossocial 
cícios localizados mais alongamento e cinco minutos de relaxamento. O programa de atividade física não supervisionado foi aplicado com base no teste ergoespirométrico, também adotado pela Instituição em função de alguns pacientes que, impossibilitados de freqüentar o serviço de condicionamento físico, eram orientados a caminhar todos os dias, por um período mínimo de 30 minutos, em lugares planos, evitando os horários mais quentes. A reavaliação e a reprogramação ocorreram em períodos em média de três meses, com a realização de um novo teste ergoespirométrico. Ao final do programa, houve aumento da capacidade física, porém os maiores benefícios descritos na tabela 2 foram observados nos pacientes que participaram do programa supervisionado.

Em resumo, a atividade física regular pós-transplante cardíaco contribui para o restabelecimento mais rápido da capacidade física, possibilitando aos pacientes voltarem a realizar a maioria de suas atividades diárias e também as recreativas mais precocemente.

\section{GUIA DE REABILITAÇÃO E CONDICIONAMENTO FÍSICO PÓS-TRANSPLANTE CARDÍACO}

\section{Classe I:}

Condições em que há evidência e/ou consenso de que dado procedimento é eficaz ou útil;

1) reabilitação física precoce

2) programa de condicionamento físico supervisionado;

3) teste de esforço de preferência com ergoespirometria, para posterior prescrição de atividade física.

\section{Classe II:}

Condição em que há evidências conflitantes e/ou divergência de opinião a respeito da utilidade e eficácia de procedimento ou tratamento;

II a - Evidência ou opinião que favorece utilidade do tratamento:

1) programa de condicionamento físico não supervisionado;

2) trabalho de resistência muscular com baixa carga;
II b - Evidência ou opinião é menos estabelecida:

1) participação em jogos competitivos sem supervisão;

2) atividade física esporádica de grande intensidade.

\section{Classe III:}

Condição em que há evidência e/ou consenso de que o procedimento/tratamento não é útil e em alguns casos pode ser nocivo.

1) instabilidade hemodinâmica;

2) episódio de rejeição de moderado a grave;

3) processo de infecção;

4) limitação clínica, ortopédica e neurológica que impossibilite a atividade física.

\section{AGRADECIMENTOS}

Agradecemos a Délcio Teixeira pela colaboração na revisão da redação.

\section{REFERÊNCIAS}

1. Gohlke H, Gohlke-Bärwolf C. Cardiac rehabilitation. Eur Heart J 1998; 19:1004-10.

2. Thompson DR, Bowman GS, Kitson AL, Bono DP, Hopkins A. Cardiac rehabilitation in the United Kingdom: guidelines and adult standards. Heart 1996;75:89-93.

3. Squires RW. Exercise training after cardiac transplantation. Med Sci Sports Exerc 1991;23:686-94

4. Ferraz AS, Arakaki H. Atividade física e qualidade de vida após transplante cardíaco. Rev Soc Cardiol Est São Paulo 1995;5:670-8.

5. Yazbek Jr P, Battistella LR. Condicionamento físico do atleta ao transplante: aspectos multidisciplinares na prevenção e reabilitação cardíaca. 1a ed. São Paulo: Sarvier - APM, 1994:201-9.

6. Kobashigawa JA, Leaf DA, Lee N, et al. A controlled trial of exercise rehabilitation after heart transplantation. N Engl J Med 1999;340:4, 272-7.

7. Lampert E, Mettauer B, Hoppeler H, et al. Skeletal muscle response to short endurance training in heart transplant recipients. J Am Coll Cardiol 1998;32:2,420-6.

8. McCartney N. Role of resistance training in heart disease. Med Sci Sports Exerc 1998;30:S396-402. 